\title{
Abnormal anatomy of the lumbosacral region imaged by magnetic resonance in children with anorectal malformations
}

\author{
H A Heij, R A J Nievelstein, I de Zwart, B W J M Verbeeten, J Valk, A Vos
}

\begin{abstract}
Objective-To investigate the frequency of lumbosacral anomalies, the association with urogenital abnormalities, and the correlation with defaecation pattern by magnetic resonance imaging (MRI).

Methods-A prospective analysis was performed of routine MRI in patients with anorectal malformations. Between 1990 and 1994, MRI was performed in 43 such patients: 31 boys and 12 girls. Twenty four had a high anorectal malformation, 16 had a low anorectal malformation, and three had Currarino's triad. MRI was performed before reconstruction in 26 , and postoperatively in 17. Urogenital anomalies were found in 21 .

Results-Abnormalities of the spinal cord and spine were found with MRI in 20 patients $(46 \cdot 5 \%)$; caudal regression syndrome in 10, tethered cord in two, a combination of both in three, and other spinal anomalies in five. These anomalies were found in $30 \%$ of the patients with low anorectal malformations, and in $\mathbf{5 0 \%}$ with high anorectal malformations. In patients with urogenital malformations, MRI more often showed spinal anomalies (13/21, $62 \%)$ than in patients without $(7 / 22,32 \%)$. In high anorectal malformations, defaecation was more often a problem in patients with spinal anomalies $(12 / 15,80 \%)$ than in patients without $(2 / 8,25 \%)$.

Conclusions-Spinal anomalies in the lumbosacral region were found with MRI in $46.5 \%$ of patients with anorectal malformations. Since presence of these anomalies seems to be related to clinical outcome, MRI should be performed routinely in all such patients.

(Arch Dis Child 1996; 74: 441-444)
\end{abstract}

Keywords: magnetic resonance imaging, anorectal malformation, caudal regression syndrome, urogenital malformations.

Netherlands

R A J Nievelstein

J Valk

Department of Radiology, Academic Medical Centre, Amsterdam, The Netherlands

I de Zwart

B W J M Verbeeten

Correspondence to:

R A J Nievelstein MD,

Department of Radiology,

Free University Hospital, PO

Box 7057, 1007 MB

Amsterdam, The

Netherlands.

Accepted 7 February 1996 mations is difficult to achieve. Despite the introduction of the posterior sagittal approach by Pena and De Vries for anatomical reconstruction of the anorectal canal and the sphincteric complex, many patients do not gain adequate control of defaecation. ${ }^{12}$

Anorectal malformations are frequently associated with anatomical and functional urogenital abnormalities. ${ }^{34}$ Duhamel described the caudal regression syndrome, consisting of lumbosacral agenesis, urogenital anomalies, and anorectal malformations. ${ }^{5}$ The impairment of sensory and motor control of the continence mechanism in this triad of anomalies may explain the poor functional results in these children. ${ }^{67}$ Magnetic resonance imaging (MRI) is a sensitive technique to detect anomalies of spinal cord and spine, including caudal regression syndrome or tethering of the spinal cord..$^{6-11}$

To gain insight in the incidence of spinal anomalies, routine MRI has been performed in our centre since 1990 in all patients with anorectal malformations. This study presents the MRI findings and explores the correlation with associated anomalies, particularly urogenital, and with the defaecation pattern.

\section{Methods}

From 1990 till 1994, routine MRI of the lumbosacral region was performed in all new patients with anorectal malformations and in some patients who had been operated on but had persisting problems.

Forty three children underwent at least one MRI examination: 31 boys and 12 girls. Twenty four had high anorectal malformations (cloacal anomaly 3, recto-urinary fistula 12 , no fistula 9), 16 had low anorectal malformations (vestibular anus 5, rectoperineal fistula 11), and three had Currarino's triad (sacral deformity, presacral tumour, and rectal stenosis). MRI was performed preoperatively in 26 children and after reconstruction in 17.

Associated anomalies were present in 31 children:

- urogenital in 21: renal agenesis 5; hydronephrosis 3; severe dysplasia 1; horseshoe kidney 1; renal cysts 2; vesico-ureteric reflux 5; ectopic ureter 1 ; severe bladder dysfunction requiring vesicostomy 3; hypospadias 3

- cardiac in 13 , causing early death in 2

- oesophageal atresia in 5

- other anomalies in 6: extremities 3; cataract 1; cleft lip 1; epilepsy 1

In 12 patients no associated anomalies were

Continence in patients with anorectal malfor- found

Up to date clinical information was obtained during recent outpatient review of all patients and reassessed for the purpose of this study. Since most of the patients were too young for a complete evaluation of anorectal function, defaecation pattern was recorded either as problematic (that is, incontinence in older children, or severe constipation requiring rectal washouts) or without problems (spontaneous and regular defaecation). 


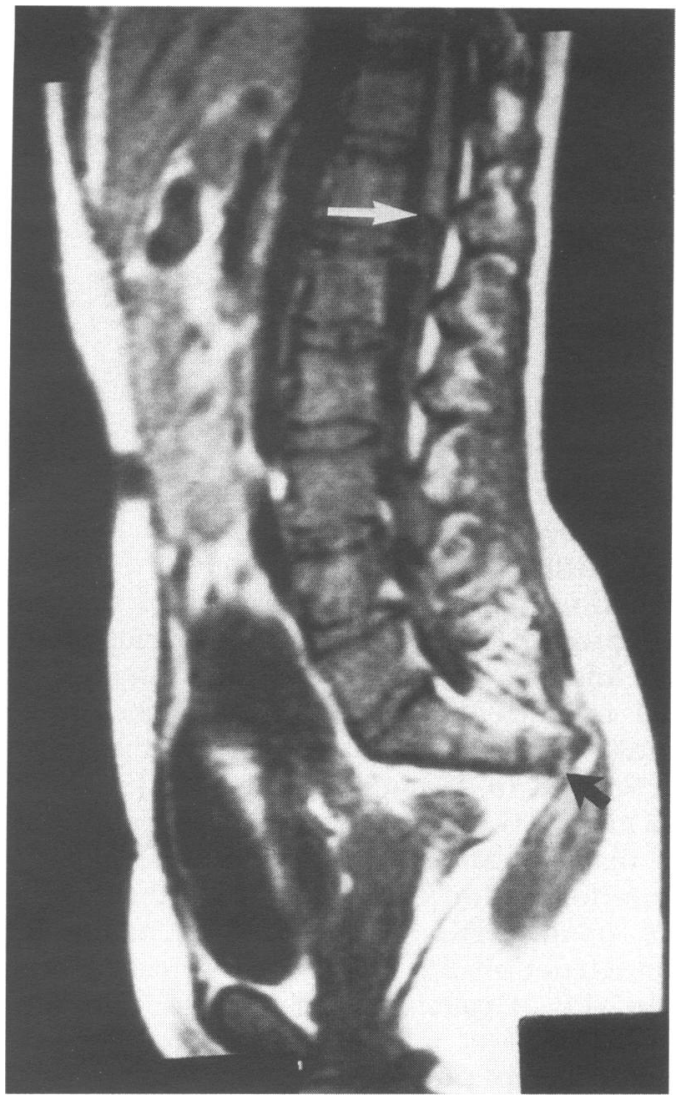

Figure 1 Sagittal spin echo T1-weighted magnetic resonance (MR) image in a girl, 16.8 years of age, with a caudal regression syndrome. There is a wedge shaped cord terminus opposite T12 (long white arrow). The vertebral column terminates at S3 (small black arrow).

MRI examination was performed under general anaesthesia in young children and under sedation in older children. The following sequences were obtained: sagittal $\mathrm{T} 1$ weighted imaging of the lumbosacral and pelvic areas; axial $\mathrm{T} 1$ weighted imaging of the lumbosacral and pelvic areas; coronal $\mathrm{T} 1$ weighted imaging of the pelvis; axial T2 weighted imaging of the lumbosacral spine.

MRI data were reviewed by staff members of

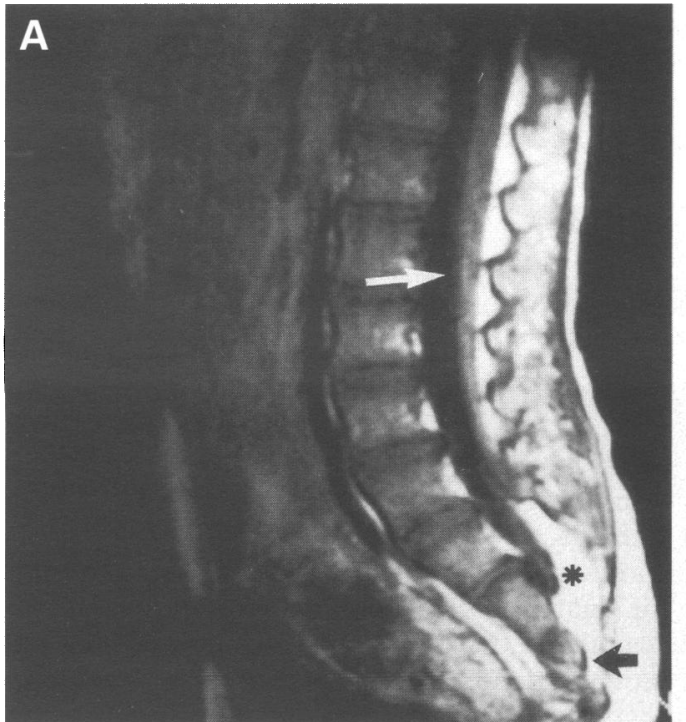

the MRI departments (RAJN, BWJMV, JV) who were unaware of the clinical data on the patients. Attention was paid to the lumbosacral spine, the medullary cone and filum terminale, and the presence of an intraspinal lipoma.

Findings were classified as:

- presence or absence of caudal regression syndrome (caudal regression syndrome)

- presence or absence of tethered cord (tethering of the spinal cord) or dysplastic cone - other bony anomalies

- presence or absence of presacral tumour.

\section{Results}

In 20 patients $(46.5 \%)$ MRI showed abnormalities of the lumbosacral spine and spinal cord: caudal regression syndrome in 10 , tethering of the spinal cord or dysplastic cone in two, other bony anomalies in two, Currarino's triad in three, a combination of tethering of the spinal cord and caudal regression syndrome in two, and tethering of the spinal cord associated with other bony anomalies in one (figs 1 and 2). The distribution of spinal anomalies in patients with low or high anorectal malformations was as follows: five of 16 patients with low anorectal malformations (30\%), 12 of 24 patients with high anorectal malformations $(50 \%)$, and three of three patients with Currarino's triad (table 1).

In the group of 21 patients with associated urogenital problems, MRI showed spinal anomalies in $13(62 \%)$ (table 2). These anomalies were found in only seven of the 22 patients without urogenital problems $(32 \%)$.

The correlation between the spinal anomalies determined by MRI and the anorectal function was also explored (table 3). Evaluation of anorectal function was possible in 36 patients. Four still have a colostomy, two died, and one was lost to follow up. Defaecation pattern was recorded as problematic in four of 13 patients with low anorectal malformations and in 15 of 23 patients with

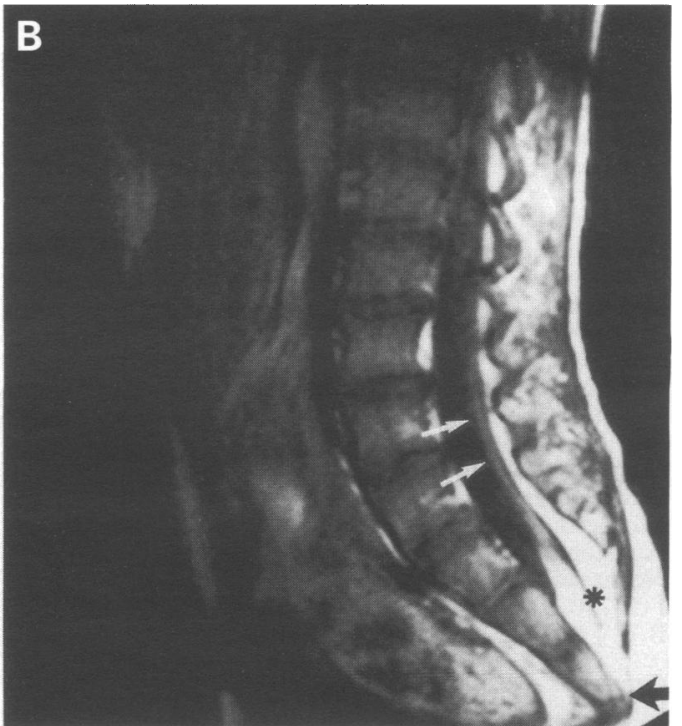

Figure 2 Sagittal spin echo T1-weighted magnetic resonance (MR) images in a boy, $5 \cdot 5$ years of age, with a tethered spinal cord and sacral agenesis. (A) Mid-sagittal MR image, showing the stretched spinal cord terminus opposite L2-L3 (long white arrow), due to a tethered filum terminale in a sacral fibrolipoma (asterisk). The vertebral column terminates at $S 3$ (small black arrow). (B) Parasagittal MR image, showing the tethered filum terminale (small white arrows) in a sacral fibrolipoma (asterisk). The vertebral column terminates at S3 (small black arrow). 
Table 1 Relation between magnetic resonance imaging (MRI) findings and level of anorectal malformation (ARM) in 43 patients

\begin{tabular}{llll}
\hline \multirow{4}{*}{$\begin{array}{l}\text { LRI } \\
\text { findings }\end{array}$} & Lovel or arm & High & Currarino's triad \\
\cline { 2 - 4 } & 11 & 12 & \\
\hline Normal & 3 & 7 & \\
CRS & 1 & 1 & \\
TC & - & 3 & \\
CRS+TC & 1 & 1 & 3 \\
Other & & & 3 \\
Currarino & 16 & 24 & \\
Total & &
\end{tabular}

CRS=caudal regression syndrome; $\mathrm{TC}=$ tethering of the spinal cord.

Table 2 Relation between magnetic resonance imaging (MRI) findings and presence of urogenital anomalies in 43 patients

\begin{tabular}{lcc}
\hline & \multicolumn{2}{l}{$\begin{array}{l}\text { Patients with } \\
\text { urological anomalies }\end{array}$} \\
\cline { 2 - 3 } MRI findings & Present & Absent \\
\hline Normal & 8 & 15 \\
CRS & 6 & 4 \\
TC & 1 & 1 \\
TC+CRS or other anomalies & 3 & - \\
Other bony anomalies & 1 & 1 \\
Currarino's triad & 2 & 1 \\
Total & 21 & 22 \\
\hline
\end{tabular}

CRS = caudal regression syndrome; TC = tethering of the spinal cord.

high anorectal malformations or Currarino's triad. In the latter category, defaecation was more often problematic in those with spinal anomalies on MRI $(12 / 15=80 \%)$ than in those without $(2 / 8=25 \%)$.

\section{Discussion}

Although anatomical reconstruction of anorectal malformations often appears succesful with the posterior sagittal approach of Pena and De Vries, the functional results are disappointing. True continence is often not achieved, but some degree of pseudocontinence with daily rectal washouts makes life tolerable for these patients. The poor functional outcome may be due to a congenital defect of the innervation of the continence mechanism. ${ }^{67}$ MRI enables adequate diagnosis of anomalies of the sacrum and distal spinal cord, such as caudal regression syndrome and tethering of the spinal cord. ${ }^{6-12}$

In this study we evaluated the MRI findings in patients with anorectal malformations. The majority of these patients ( 31 out of 43 ) had

Table 3 Relation between magnetic resonance imaging (MRI) findings and defaecation pattern in 13 patients with low anorectal malformation ( $A R M$ ) and 23 patients with high ARM and Currarino's triad

\begin{tabular}{lllr}
\hline & \multicolumn{2}{c}{ Defaecation pattern } \\
\cline { 2 - 4 } MRI findings & No problems & Problematic & Total \\
\hline Low ARM & 5 & 3 & \\
Normal & 4 & 1 & 5 \\
Abnormal & 9 & 4 & 13 \\
Total & 6 & 3 & \\
High ARM & and Currarino's triad & 12 & 9 \\
Normal & 2 & 15 & 14 \\
Abnormal & 8 & & 23 \\
Total & & & \\
\hline
\end{tabular}

multiple congenital malformations: only 12 had no other anomalies.

Malformations of spinal cord and spine (that is, caudal regression syndrome, tethering of the spinal cord, a combination of these two or other anomalies) were present on MRI in half of the patients with anorectal malformations. Although the incidence was higher in patients with high anorectal malformations (50\%), the incidence in patients with low malformations was by no means negligible (30\%). Similar findings have been reported before. ${ }^{7-10}$

In patients with associated urogenital anomalies MRI showed spinal anomalies more often than in those without ( $62 \%$ versus $36 \%$ ), a finding that confirms the data of others. ${ }^{347}$ In addition, De Gennaro et al stated that the presence of spinal anomalies, even if clinically silent, justifies repeated urodynamic testing to detect as early as possible the onset of deterioration before irreversible neurological damage has occurred. ${ }^{7}$

Our data also suggest a strong correlation between an abnormal defaecation pattern and spinal anomalies determined by MRI, especially in patients with high anorectal malformations $(12 / 15=80 \%)$. Although this may partly be due to patient selection, since we only included postoperative patients with persistent problems, it seems likely that the presence of spinal congenital anomalies also affects the innervation of faecal control. This is supported by necropsy and peroperative findings by others, well summarised by Stephens and Smith. ${ }^{13}$

Since most of the patients were too young for a thorough evaluation of fecal continence, follow up of anorectal and urodynamic function at an older age will be needed. In this respect it should also be mentioned that our initial optimism regarding anorectal function in patients with Currarino's triad has not been sustained. ${ }^{14}$

Ultrasound of the spinal cord and spine has been advocated as a screening method for patients with anorectal malformations. ${ }^{15}$ Since the available data are still scarce, confirmation of these findings in larger series should be awaited before suggesting that MRI be reserved for patients with abnormal ultrasound findings only.

It is evident that MRI is an important diagnostic tool in patients with anorectal malformations since it enables identification of those with associated spinal anomalies, such as caudal regression syndrome and tethering of the spinal cord. These patients more often have urogenital problems, and therefore require careful follow up to prevent renal failure in the long term. Surgical release of tethering of the spinal cord may be indicated to prevent neurological deterioration. Since caudal regression syndrome or tethering of the spinal cord may be associated with impaired anorectal function, it is important to pinpoint these patients at an early age and to guide their management accordingly. Therefore, we advocate that MRI is performed routinely in all patients with anorectal malformations. 
1 Langemeijer RATM, Molenaar JC. Continence after pos terior sagittal anorectoplasty. $\mathcal{F}$ Pediatr Surg $1991 ; 26$ 587-90.

2 Mulder W, de Jong E, Wauters I, Kinder M, Heij HA, Vos A. Posterior sagittal anorectoplasty: functional results of primary and secondary operations in comparison to the pull-through method in anorectal malformations. Eur $f$ Pediatr Surg 1995; 5: 170-3.

3 Boemers TM, Gool JD van, de Jong TPVM, Bax NMA Urodynamic evaluation of children with the caudal regresUrodynamic evaluation of children with the caudal regres-
sion syndrome (caudal dysplasia sequence). $₹$ Urol 1994 ; 151: $1038-40$.

4 Kakizaki H, Nonomura K, Asano Y, Shinno Y, Ameda K, Koyanagi $T$. Preexisting neurogenic voiding dysfunction in children with imperforate anus: problems in management. F Urol 1994; 151: $1041-4$.

5 Duhamel B. From the mermaid to anal imperforation: the syndrome of caudal regression. Arch Dis Child 1961; 36: $152-5$.

$6 \mathrm{Li} \mathrm{L,} \mathrm{Li} \mathrm{Z,} \mathrm{Wang} \mathrm{LY,} \mathrm{Xiao} \mathrm{FD.} \mathrm{Anorectal} \mathrm{anomaly:}$ neuropathological changes in the sacral spinal cord. f Pediatr Surg 1993; 28: 880-5.

7 De Gennaro M, Rivosecchi M, Lucchetti MC, Silveri M, Fariello G, Schingo P. The incidence of occult spinal dysraphism and the onset of neurovesical dysfunction in children with anorectal anomalies. Eur $\mathcal{f}$ Pediatr Surg
1994; 4: 12-14.

8 Tunell WP, Austin JC, Barnes PD, Reynolds A. Neuroradiologic evaluation of sacral abnormalities in imperforate anus complex. $\mathcal{F}$ Pediatr Surg 1987; 22: 58-61.

9 Karrer FM, Flannery AM, Nelson MD, McLone DG Raffensperger JG. Anorectal malformations: evaluation of associated spinal dysraphic syndromes. $f$ Pediatr Surg 1988; 23: 45-8.

10 Davidoff AM, Thompson CV, Grimm JK, Shorter NA, Filston HC, Oakes WJ. Occult spinal dysraphism in patients with anal agenesis. F Pediatr Surg 1991; 26: 1001-5.

11 Nievelstein RAJ, Valk J, Smit LME, Vermeij-Keers C. MR of the caudal regression syndrome: embryologic implications. Am $\mathcal{f}$ Neuroradiol 1994; 15: 1021-9.

12 Sachs TM, Applebaum H, Touran T, Taber $P$, Darakjian A. Colleti P. Use of MRI in evalua alies. F Pediatr Surg 1990; 25: 817-21.

13 Stephens FD, Smith ED, eds. Anorectal malformations in children: update 1988. Birth Defects, Original Article Series 1988;24(4)

14 Heij HA, Moorman-Voestermans CGM, Vos A, Kneepkens CMF. Triad of anorectal stenosis, sacral anomaly and presacral mass: a remediable cause of severe constipation Br F Surg 1990; 77: 102-4.

15 Beek FJA. Ultrasound of the lower spinal canal in infants. Utrecht: University of Utrecht, 1995. Thesis. 